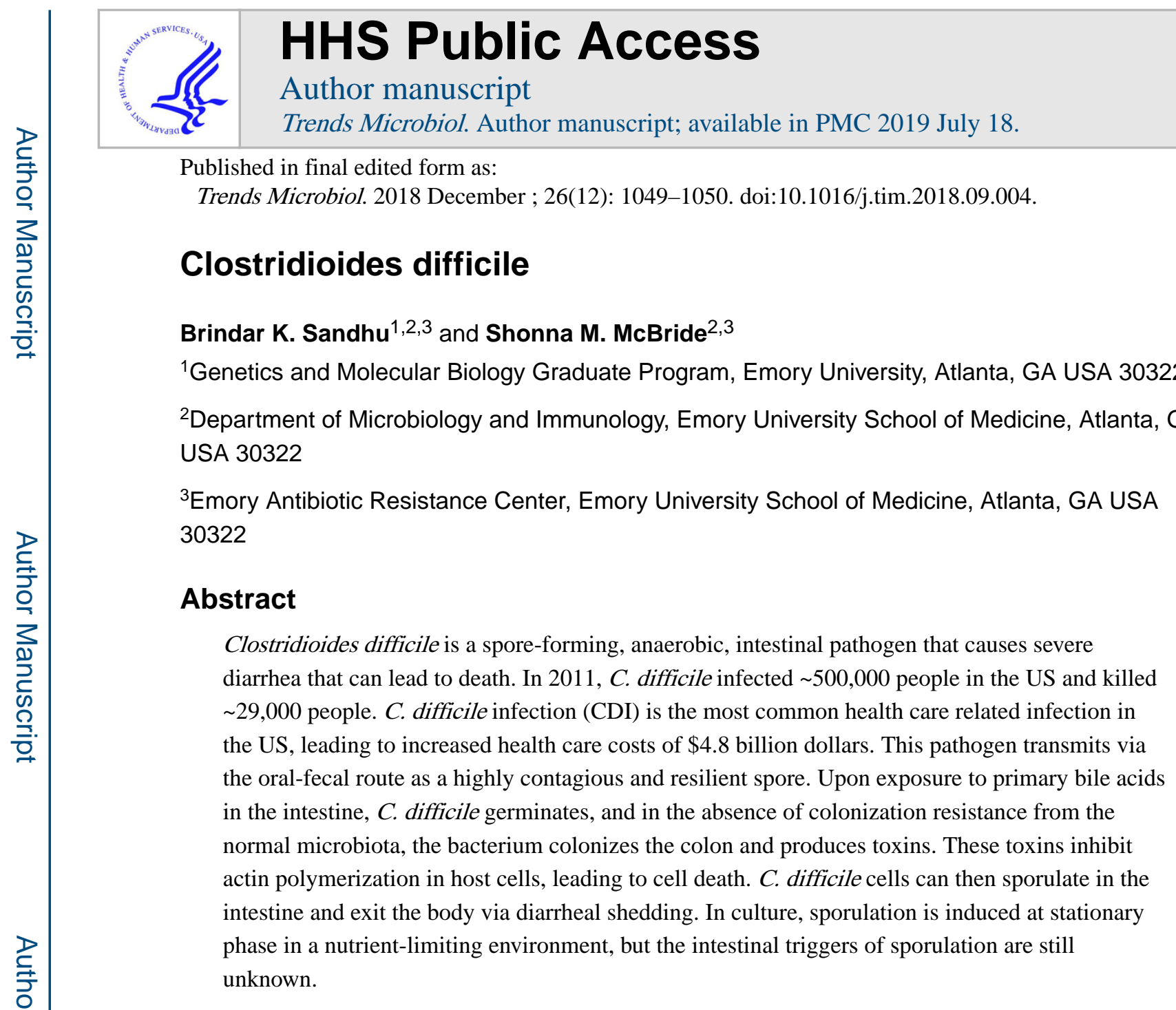

\title{
Key Facts:
}

- C. difficile was first described in 1935, but wasn't linked to antibiotic-associated diarrhea and pseudomembranous colitis until 1978.

- $\quad$ C. difficile has a single, circular chromosome comprised of approximately 4.3 $\mathrm{Mb}$.

- C. difficile spores are resistant to heat, oxygen, and ethanol-based disinfectants, but can be killed by a 1:10 dilution of sodium hypochlorite (bleach).

- $\quad$ CDI animal models include the hamster, mouse, young hare, infant pig, prairie dog, foal, quail, and, recently, the rat.

- $\quad$. difficile toxin action has been characterized in the rat, mouse, hamster, rabbit, guinea pig, infant rhesus monkey, and the zebrafish embryo.

- $\quad$ The two major toxins produced by $C$. difficile are TcdA and TcdB, which are glucosyltransferases that inhibit Rho, Rac, and Cdc42. A third toxin, Cdt, is found in the ribotype 027 strain. 


\title{
Disease Facts:
}

- $\quad$ People most at risk for CDI are the elderly, people in healthcare settings, and those who have received antibiotic treatment.

- The antibiotics that provide the highest risk of CDI are clindamycin, floroquinolones, cephalosporins, monobactams, and carbapenems, with increased risk correlated with greater cumulative dose, number of antibiotics, and duration of exposure.

- The estimated rate of CDI recurrence is $13.5 \%$ and death is $1.3 \%$, both within the first 30 days of initial infection.

\section{Taxonomy and classification:}

\author{
Kingdom: Bacteria \\ Phylum: Firmicutes \\ Class: Clostridia \\ Order: Clostridiales \\ Family: Clostridiaceae
}

Genus: Clostridioides (formerly Peptoclostridium and Clostridium)

Species: difficile

Gram-positive

\section{ACKNOWLEDGEMENTS}

Details of toxin effects are adapted from Abt et al. (2016). Work in the McBride lab is supported by the U.S. National Institutes of Health through research grants A1121684 and A1116933 to S.M.M. The content of this manuscript is solely the responsibility of the authors and does not necessarily reflect the official views of the National Institutes of Health.

\section{literature}

1. Lessa FC, et al., Burden of Clostridium difficile Infection in the United States. New England Journal of Medicine, 2015 372(9): p. 825-834. [PubMed: 25714160]

2. Dubberke ER and Olsen MA, Burden of Clostridium difficile on the Healthcare System. Clinical Infectious Diseases, 2012 55: p. S88-S92. [PubMed: 22752870]

3. Raibaud P, et al., Sodium Taurocholate, a Germination Factor for Anaerobic Bacterial-Spores Invitro and Invivo. Annales De Microbiologie, 1974 B125(3): p. 381-391.

4. Voth DE and Ballard JD, Clostridium difficile toxins: Mechanism of action and role in disease. Clinical Microbiology Reviews, 2005 18(2): p. 247-+. [PubMed: 15831824]

5. Hall IC and O'Toole E, Intestinal flora in new-borin infants - With a description of a new pathogenic anaerobe, Bacillus difficilis. American Journal of Diseases of Children, 1935 49(2): p. 390-402.

6. Bartlett JG, et al., Role of Clostridium-Difficile in Antibiotic-Associated Pseudomembranous Colitis. Gastroenterology, 1978 75(5): p. 778-782. [PubMed: 700321] 
7. Best EL, Freeman J, and Wilcox MH, Models for the study of Clostridium difficile infection. Gut Microbes, 2012 3(2): p. 145-167. [PubMed: 22555466]

8. Oka K, et al., Establishment of an Endogenous Clostridium difficile Rat Infection Model and Evaluation of the Effects of Clostridium butyricum MIYAIRI 588 Probiotic Strain. Front Microbiol, 2018 9: p. 1264. [PubMed: 29967595]

9. Hutton ML, et al., Small animal models for the study of Clostridium difficile disease pathogenesis. Fems Microbiology Letters, 2014 352(2): p. 140-149. [PubMed: 24372713]

10. Abt MC, McKenney PT, and Pamer EG, Clostridium difficile colitis: pathogenesis and host defence. Nature Reviews Microbiology, 2016 14(10): p. 609-620. [PubMed: 27573580] 


\section{1}

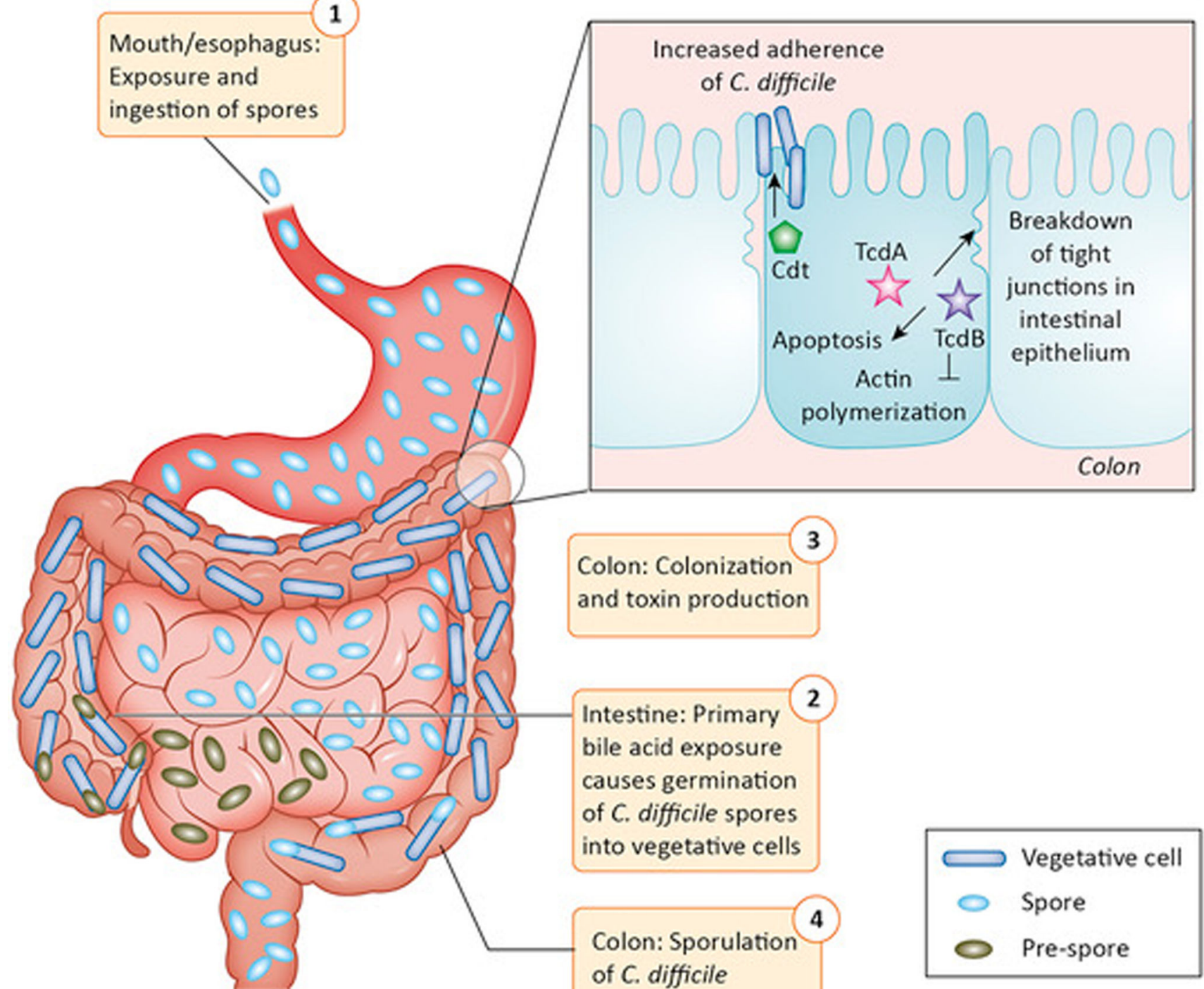

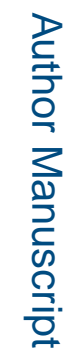




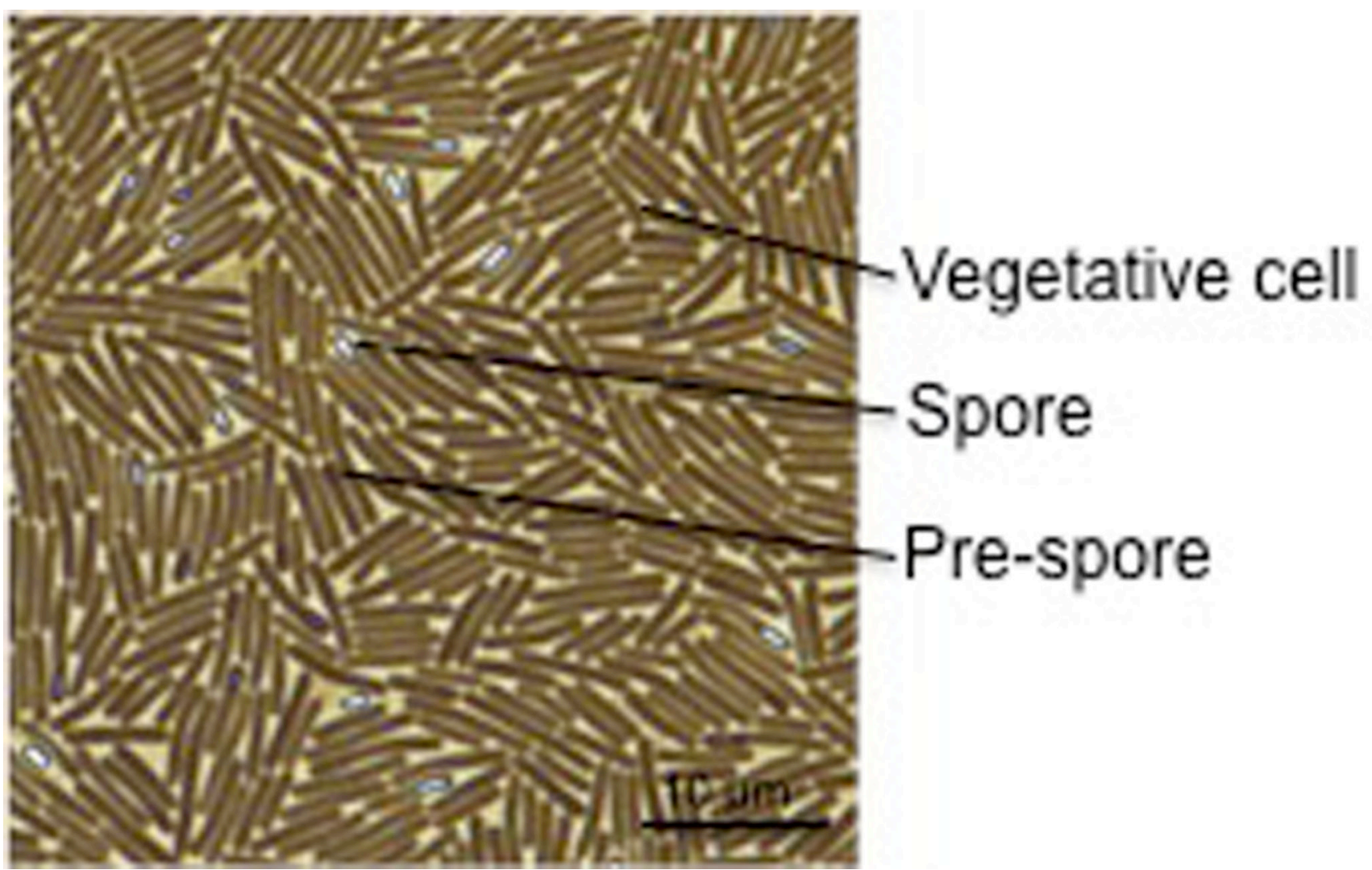

